This item was submitted to Loughborough's Research Repository by the author.

Items in Figshare are protected by copyright, with all rights reserved, unless otherwise indicated.

\title{
Investigation of environmental low-frequency noise
}

PLEASE CITE THE PUBLISHED VERSION

http://dx.doi.org/10.1016/S0003-682X(96)00059-X

PUBLISHER

(c) Elsevier

VERSION

AM (Accepted Manuscript)

LICENCE

CC BY-NC-ND 4.0

REPOSITORY RECORD

Krylov, Victor V.. 2013. "Investigation of Environmental Low-frequency Noise". figshare. https://hdl.handle.net/2134/11511. 
This item was submitted to Loughborough's Institutional Repository (https://dspace.lboro.ac.uk/) by the author and is made available under the following Creative Commons Licence conditions.

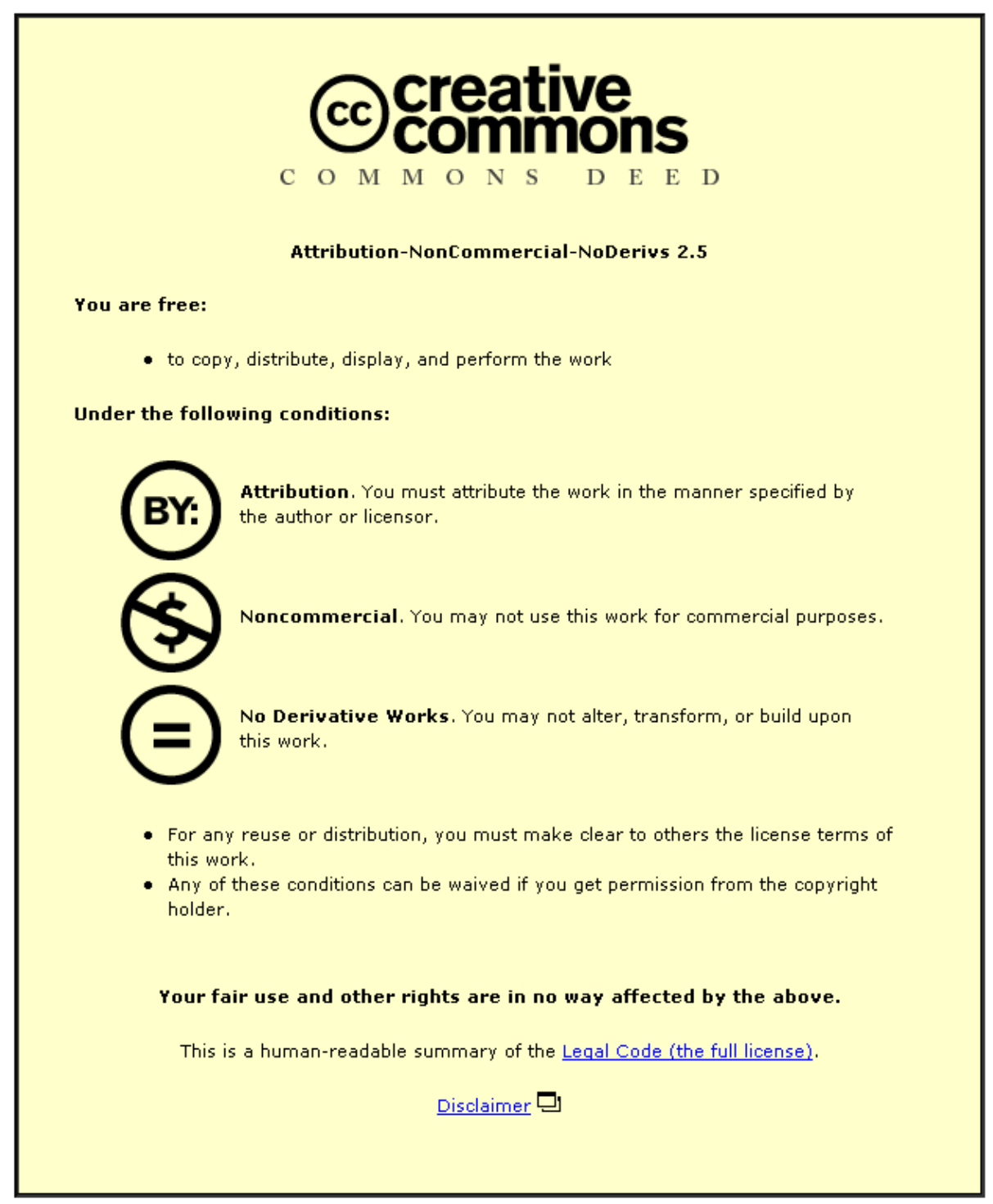

For the full text of this licence, please go to: http://creativecommons.org/licenses/by-nc-nd/2.5/ 


\title{
Investigation of Environmental Low-Frequency Noise
}

\author{
V. V. Krylov \\ Centre for Research into the Built Environment, Nottingham Trent University, \\ Burton Street, Nottingham NG1 4BU, UK
}

\begin{abstract}
The paper describes the results of theoretical and experimental investigation of environmental low-frequency noise and vibration. The main aim of this investigation was to check up the popular belief that this noise is being generated by underground gas pipes. The theoretical hypothesis has been developed which shows that under certain circumstances underground gas pipes may be in fact one of the sources of low-frequency noise. According to this hypothesis, underground pipes are able to effectively generate Rayleigh surface waves in the ground. Then, propagating to the buildings, these waves can result in generating structure-borne noise in buildings. The experimental investigations of the low-frequency noise and vibration were carried out in several locations over the East Midlands (UK) and included high resolution measurements of noise and vibration spectra. Records were taken inside and outside the houses, as well as near buried gas distribution lines. In 50\% of cases the low frequency noise complained of has been detected. However, the presence of ground vibrations was not
\end{abstract}


observed in any location. Thus, at least during this series of experiments, there was no evidence of underground gas pipes being a source of low frequency noise. The measured characteristics of the air-borne noise show that as a rule its level is below the average threshold of human sensitivity. Thus, only exceptionally sensitive people can be affected. Nevertheless, even though a number of people sensitive to low-frequency noise is relatively small, the technical and legal aspects of this problem deserve further consideration.

\section{INTRODUCTION}

The present paper describes the results of theoretical and experimental research into the environmental low-frequency noise, also called the low-frequency hum. This phenomenon has been known in the United Kingdom and in some other countries for at least two decades (see, e.g. [1,2]). However, in many aspects its nature and even the existence itself are still questionable. In particular, despite the established facts of devastating effects of low-frequency noise on people $[3,4]$, many representatives of the medical profession deny the objective existence of the environmental lowfrequency noise and link all the complaints to human aural disorders, such as tinnitus. Although a current number of complaints about environmental low-frequency noise (around 500 a year in the UK along) makes just a small fraction of a total number of noise complaints, the phenomenon deserves careful consideration. In particular, the questions need to be answered whether the 
Investigation of environmental low-frequency noise

environmental low-frequency noise objectively exists and, if so, what are its main physical mechanisms and sources.

Several studies have been carried out so far to assess the environmental low-frequency noise (see, e.g., [1-7]). The latest measurements were performed by British Gas [5] and jointly by Building Research Establishment (BRE) along with Sound Research Laboratories (SRL) on behalf of Department of the Environment [6,7]. The British Gas report states that in seven cases out of thirtythree the disturbing noise sources were identified. In one case the noise was caused by the pipework at a British Gas installation. Others were related to a refrigerator unit in a nearby plant, a power unit on a ship, an industrial burner, a distant shipyard, machinery in a factory, and a resonating flue liner in the complainant's home. Unfortunately, no information is given in [5] about the frequencies and the amplitudes of sound from the identified sources. The results of the recent BRE/SRL study [6,7] are generally negative: only in three cases out of thirty-one the noise was detected. In two cases it was the $100 \mathrm{~Hz}$ noise caused by electric substations, and in one case it was the $104 \mathrm{~Hz}$ noise of unknown origin which could be heard by the investigator only inside the house. In all these three cases of BRE/SRL study one can speak about comparatively high-frequency noise which is not the main subject for complaints of low-frequency noise sufferers . Regarding such complaints which specify the disturbing noise as close to infrasound, one should admit that neither low-frequency noise itself, nor its sources have been identified in [6,7], although it has been mentioned there that in seven cases "there was some evidence to suggest that a low level low frequency noise may occasionally be present that could be related to the noise complained of”. Note that in all existing investigations only 
air-borne noise has been measured. Despite a lot of suspicions shared by many sufferers that "noise comes from the ground” no measurements of ground vibrations have been made.

In the present paper we concentrate on the most popular belief among the low-frequency noise sufferers on the possible sources of the noise. Namely, that the main sources of the disturbing lowfrequency noise (hum) are underground gas pipes. In addition to the theoretical estimate of the expected noise and vibration levels under the mechanism responsible for such generation, we report the results of our recent experimental investigations carried out in several locations over the East Midlands (UK). In addition to measurements of air-borne noise, these measurements also included measurements of ground vibrations, as well as vibrations of the house walls. Finally, we discuss the obtained results and derive the main conclusions.

\section{UNDERGROUND GAS PIPES AS POSSIBLE SOURCES OF LOW-FREQUENCY NOISE}

In our opinion, there may be different sources and mechanisms of low-frequency noise which may cause annoyance and distress of some people. In addition to the above mentioned sources identified in the British Gas report [5], one can mention railway and road traffic [8-11], flow machines [12], railway and highway bridges [13,14], numerous industrial installations, long chimneys, wind farms, etc. Apart from this variety of man-made sources, there might be different mechanisms of lowfrequency noise generation in the natural environment, e.g., sounds caused by wind blowing over the mountains, infrasound generated by water waves during storms (the so called "voice of the sea”), 
Investigation of environmental low-frequency noise

etc. However, the most popular belief among people affected by the low-frequency noise is that sources of this noise are underground gas pipes, especially those related to National Distribution System.

To inspect the idea that underground gas pipes can be the sources, we developed the hypothesis which employs the most likely generation mechanism associated with pipes. According to this hypothesis, the low-frequency noise inside the houses is structure-borne sound caused by ground vibrations propagating to buildings as surface Rayleigh waves. We analyse the possibility when the sources of these surface waves are buried gas pipes in which turbulent flows of gas or liquid generate sound waves of high amplitude propagating in pipe-lines as in waveguides. The suggested mechanism of generation is as follows. The velocities of sound $c_{0}$ inside the pipes $(450 \mathrm{~m} / \mathrm{s}$ for methane) may be often higher than the velocities of Rayleigh surface waves $c_{R}$ in the ground at the frequencies of interest $(5-50 \mathrm{~Hz})$. Typical values of $c_{R}$ are $300-600 \mathrm{~m} / \mathrm{s}$. If $c_{0}>c_{R}$, then ground Rayleigh waves are expected to be effectively generated by sound waves propagating inside the pipes [15]. The physical nature of this phenomenon is similar to that of sound boom from supersonic jets or to that of recently predicted Rayleigh ground wave boom from high-speed trains [16,17]. In the following paragraphs we discuss the feasibility of this generation mechanism and give theoretical estimate of the expected noise and vibration.

Assume that a gas or petrol pipe of radius $a$ and wall thickness $d$ is buried at a depth $h$ (Fig.1). Let us consider propagation of a time-harmonic sound wave inside this pipe (the lowest waveguide mode): 


$$
p(x, t)=p_{0} \exp \left[i\left(k_{0} x-\omega t\right)\right]
$$

Here $p(x, t)$ is time- and space-dependent sound pressure, $p_{0}$ is the sound pressure amplitude, $k_{0}=$ $\omega / c_{0}$ is the sound wavenumber, $\omega=2 \pi f$ is circular frequency, and $c_{0}$ is the velocity of sound in pipe gas. We recall that total pressure inside the pipe is $P(x, t)=P_{s t}+p(x, t)$, where $P_{s t}$ is a static pressure. The sources of sound wave excitation inside pipes may be of different nature. These may be, for example, powerful compressors in gas compressor stations or instabilities of gas flows in pipes themselves. We will not discuss these particular reasons here, considering the sound amplitude $p_{0}$ as a given value.

Propagation of a sound wave in the pipe causes displacements of the pipe walls which in turn can generate elastic waves in the adjacent ground. Ignoring reaction of the ground on pipe deformations and using quasi-static solution of thin shell equations $[18,19]$, one can obtain the expressions for sound-induced radial and horizontal displacements of the pipe walls respectively

$$
\begin{gathered}
w=\left(a^{2} / E d\right) p(x, t), \\
v=i\left(a \sigma / E d k_{0}\right) p(x, t),
\end{gathered}
$$

where $E$ and $\sigma$ are Young's modulus and Poisson's ratio of the pipe material. 
The next step in the solution is to determine the amplitudes of elastic fields generated in the bulk of the ground due to the sound-induced displacements of pipe walls (2), (3). Introducing cylindrical coordinates $r, x$ associated with the pipe axis, we can express radial and horizontal displacements in the ground in terms of the elastic potentials $\varphi$ and $\psi$ :

$$
\begin{aligned}
& u_{r}=\partial \varphi / \partial r+\partial^{2} \psi / \partial r \partial x \\
& u_{x}=\partial \varphi / \partial x-\partial^{2} \psi / \partial r^{2}-(1 / r) \partial \psi / \partial r
\end{aligned}
$$

Quantities $\varphi$ and $\psi$ describe potential and vortex parts of the elastic field respectively and satisfy the wave equations:

$$
\begin{aligned}
& \Delta \varphi-\left(1 / c_{l}\right) \partial^{2} \varphi / \partial^{2}=0, \\
& \Delta \psi-\left(1 / c_{t}\right) \partial^{2} \psi / \partial^{2}=0,
\end{aligned}
$$

where $\Delta=\partial^{2} / \partial^{2}+(1 / r) \partial / \partial r+\partial^{2} / \partial x^{2}$ is the Laplace operator written in cylindrical coordinates, $c_{l}$ and $c_{t}$ are velocities of longitudinal and shear bulk waves in the ground. On the pipe walls, i.e., at $r$ $=a$, the displacements of the ground, $u_{r}$ and $u_{x}$, should satisfy the boundary conditions

$$
\begin{aligned}
& u_{r}=w, \\
& u_{x}=v,
\end{aligned}
$$

where $w$ and $v$ are determined by (2), (3). 
The solution of the boundary value problem (2) - (8) is sought in the form

$$
\begin{aligned}
& \varphi=A H_{0}^{(1)}\left(v_{l} r\right) \exp \left[i\left(k_{0} x-\omega t\right)\right], \\
& \psi=B H_{0}^{(1)}\left(v_{t} r\right) \exp \left[i\left(k_{0} x-\omega t\right)\right],
\end{aligned}
$$

where $H_{0}^{(1)}\left(v_{l, t} r\right)$ is the Hankel function of the first kind and zero order, $v_{l, t}=\left(k_{l, t}{ }^{2}-k_{0}^{2}\right)^{1 / 2}, k_{l}=\omega / c_{l}$ and $k_{t}=\omega / c_{t}$ are the wavenumbers of longitudinal and shear bulk waves, $A$ and $B$ are yet unknown coefficients. Note that (9), (10) satisfy the equations (6), (7) respectively. Obviously, if $k_{l, t}{ }^{2}>k_{0}^{2}$, then $\varphi$ and $\psi$ in (9), (10) describe conical longitudinal and shear elastic waves propagating away from the pipe. In the opposite case, $k_{l, t}{ }^{2}<k_{0}{ }^{2}$, expressions (9), (10) describe localised quasi-static elastic fields accompanying the sound wave and travelling along the pipe at speed $c_{0}$.

Coefficients $A$ and $B$ are determined from the boundary conditions (8). Using the lowfrequency approximation for the Hankel function $H_{0}^{(1)}\left(v_{l, t} r\right)=(2 \mathrm{i} / \pi) \ln \left(v_{l, t} r\right)$, valid for $v_{l, t} r<<1$, and substituting (9), (10) into (4), (5), (8), (2), (3), one can obtain the following expressions for $A$ and $B$ :

$$
\begin{aligned}
& A=-\left[i \pi a \sigma / 2 E d k_{0}^{2} \ln \left(v_{l} a\right)\right] p_{0} \\
& B=\left[\left(\pi a \sigma / 2 E d k_{0}^{3} \ln \left(v_{l} a\right)-\left(\pi a^{3} / 2 E d k_{0}\right)\right] p_{0} .\right.
\end{aligned}
$$

It is easy to see from (11), (12) and (4), (5) that contributions of $\varphi$ and $\psi$ to the ground displacement field are of the same order. Both these potentials are equally important and contribute additively to generating Rayleigh surface waves at the ground surface. However, to demonstrate the 
Investigation of environmental low-frequency noise

effect in principle, we consider here only contribution of the potential $\varphi$. This essentially simplifies the problem yet allowing to achieve satisfactory estimation for the order of amplitudes of generated Rayleigh waves.

To calculate the amplitudes of elastic fields generated at the ground surface by the waves (9)-(12) one should solve the corresponding boundary-value problem for the elastic half-space. Excitation of longitudinal and shear elastic waves in the elastic half space by longitudinal conical waves in the form (9) has been earlier considered in the paper [20]. According to this paper, the general integral representation of the ground surface vertical displacement associated with the excited elastic field has the form

$$
u_{z}=D \int_{-\infty}^{\infty} \frac{2 \mathrm{k}_{\mathrm{t}}^{2}\left[2\left(\mathrm{k}^{2}+\mathrm{k}_{0}^{2}\right)-\mathrm{k}_{\mathrm{t}}^{2}\right] \exp \left[\mathrm{i}\left(\mathrm{ky}+\mathrm{k}_{0} \mathrm{x}+\mathrm{ihs}_{\mathrm{t}}-\omega \mathrm{t}\right)\right]}{\mathrm{F}\left(\sqrt{\mathrm{k}^{2}+\mathrm{k}_{0}^{2}}\right)} d k
$$

where $k$ is a current wavenumber, $D=-2 i A / \pi$ is the amplitude coefficient, $F\left(\sqrt{k^{2}+k_{0}^{2}}\right)=\left[2\left(k^{2}\right.\right.$ $\left.\left.+k_{0}^{2}\right)-k_{t}^{2}\right]^{2}-4\left(k^{2}+k_{0}^{2}\right) s_{l} S_{t}$ is the Rayleigh determinant as a function of $\sqrt{k^{2}+k_{0}^{2}}$ (instead of $k$ in usual notation), and $s_{l, t}=\left(k^{2}+k_{0}^{2}-k_{l, t}^{2}\right)^{1 / 2}$. Evaluation of the integral (13) with regard to calculation of generated bulk elastic waves has been carried out in the complex $k$-plane by the method of steepest descents [20]. Note that calculations in [20] were performed for high-frequency bulk longitudinal and shear elastic waves, with applications to active acoustic detection of leaks in underground gas distribution lines. 
From the point of view of examining possible mechanisms of low-frequency hum, we need to investigate generation of Rayleigh surface waves which carry most of the energy of generated lowfrequency ground vibrations. To calculate radiated Rayleigh waves we have to take contribution of a residue of the integrand in (13) at $k$ corresponding to $F\left(k^{2}+k_{0}^{2}\right)=0$, i.e., at $k=\sqrt{k_{R}{ }^{2}-k_{0}^{2}}$, where $k_{R}=\omega / c_{R}$ is the Rayleigh wavenumber and $c_{R}$ is Rayleigh wave velocity After simple manipulations, this results in the following expression for the vertical component of the surface ground vibration velocity, $v_{z}=\partial u_{z} / \partial$, associated with generated Rayleigh waves:

$$
\begin{aligned}
v_{z}= & -\frac{2 p_{0} \pi a \sigma}{E d k_{0}^{2} \ln \left(v_{1} a\right)} \omega \frac{2 k_{t}^{2}\left(2 k_{R}{ }^{2}-k_{t}^{2}\right)}{\left[F^{\prime}\left(k_{R}\right) / k_{R}\right] \sqrt{{k_{R}}^{2}(1+2 i \gamma)-k_{0}^{2}}} \exp \left[-h\left(k_{R}^{2}-k_{l}^{2}\right)^{1 / 2}+\right. \\
& \left.i k_{0} x \pm i\left[k_{R}^{2}(1+2 i \gamma)-k_{0}^{2}\right]^{1 / 2} y\right] .
\end{aligned}
$$

Here $F^{\prime}\left(k_{R}\right)$ is the derivative $d F / d k$ of the "usual" Rayleigh determinant $F(k)=\left(2 k^{2}-k_{t}^{2}\right)^{2}$ $4 k^{2}\left(k^{2}-k_{l}^{2}\right)^{1 / 2}\left(k^{2}-k_{t}^{2}\right)^{1 / 2}$ taken at $k=k_{R}$, signs “+” and “-” in the exponential of (14) correspond

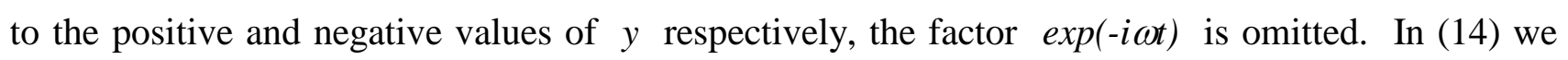
also have taken into account ground attenuation of Rayleigh waves where it is essential: in the exponential and in the denominator (otherwise a singularity could be expected when $k_{R}=k_{0}$ ). We have accounted for attenuation in a traditional way: via replacing real wavenumber $k_{R}$ by its complex value $k_{R}(1+i \gamma)$, where $\gamma$ is the attenuation constant of the ground. It is assumed that sound waves inside the pipe propagate without attenuation. 
Investigation of environmental low-frequency noise

According to the formula (14), radiation of Rayleigh waves in the ground takes place only for $k_{R}>k_{0}$, i.e., for $c_{R}<c_{0}$, i.e., similarly to a sonic boom from supersonic jets or to a ground Rayleigh wave boom from superfast trains [16,17]. This may happen quite often since, e.g., the velocity of sound inside the pipe filled with methane is $450 \mathrm{~m} / \mathrm{s}$ and the velocities of Rayleigh surface waves in the ground are typically $300-600 \mathrm{~m} / \mathrm{s}$. It is seen that generated Rayleigh waves are quasi-plane waves propagating symmetrically with respect to the $x$-axis at the angles $\Theta=\cos ^{-1}\left(c_{R} / c_{0}\right)$ (Fig.1). If $c_{0}<c_{R}$ then Rayleigh waves are not generated and formula (14) describes the quasi-static elastic field accompanying the sound wave and exponentially decaying with distance $y$ from the pipe. The

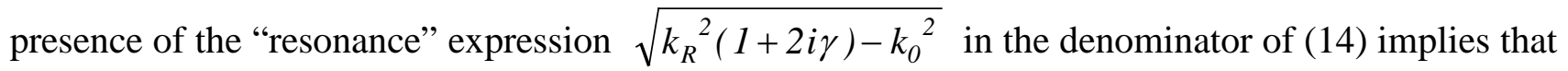
for $k_{R}>k_{0}$ the most efficient generation of Rayleigh waves is expected at $k_{R} \approx k_{0}$, i.e., at $c_{R} \approx c_{0}$. Maximum achievable Rayleigh wave amplitudes in this case are determined by the ground attenuation factor $\gamma$.

We recall that formula (14) describes radiation caused by time-harmonic sound wave (1) propagating in a pipe. If the sound wave in the pipe is not time-harmonic, as for example in the case of sound generation by turbulent flows [21,22], then multiplication of (14) by the frequency spectrum of sound gives the spectral density of generated Rayleigh waves. One can assume that in the frequency range of interest $(5-50 \mathrm{~Hz})$ the spectrum of sound in the pipe is approximately uniform with a spectral density $p_{0}$. Then formula (14) represents straightway the spectrum of Rayleigh waves generated by the pipe.

Numerical calculations of the ground vibration amplitudes $V=\left|v_{z}\right|$ have been carried out according to the formula (14) for the following parameters of the pipe and ground: $a=0.5 \mathrm{~m}, d=$ 
$0.005 \mathrm{~m}, E=2010^{10} \mathrm{~N} / \mathrm{m}, \sigma=0.31$ (tempered steel), $c_{0}=450 \mathrm{~m} / \mathrm{s}, p_{0}=100 \mathrm{~dB}$ (relative to the amplitude of $2 \sqrt{2} 10^{-5} \mathrm{~N} / \mathrm{m}^{2}$ ); Poisson ratio of the ground was taken as 0.25 ; pipe depth $h$ varied from $0.5 \mathrm{~m}$ to 1.5 , Rayleigh wave velocity of the ground varied from $400 \mathrm{~m} / \mathrm{s}$ to $500 \mathrm{~m} / \mathrm{s}$, and ground attenuation $\gamma$ varied from 0.005 to 0.015; observation distance from the pipe $y$ varied from $25 \mathrm{~m}$ to $100 \mathrm{~m}$.

Figure 2 shows Rayleigh wave ground vibration spectra for three values of pipe-depth: $h=0.5$, 1.0 and $1.5 \mathrm{~m}$ (curves V1, V2, and V3 respectively). Here $c_{R}=440 \mathrm{~m} / \mathrm{s}, y=50 \mathrm{~m}$ and $\gamma=$ 0.005. One can see that generated spectra have maxima with the magnitudes and locations dependent on $h$. The lower the $h$ values, the higher the central frequencies and the larger the amplitudes of generated waves.

Figure 3 represents ground vibration amplitudes as functions of Rayleigh wave velocity in the ground $c_{R}$ for three values of attenuation: $\gamma=0.005,0.010$, and 0.015 (curves V1, V2, and V3 respectively). Distance $y$ has been chosen as $50 \mathrm{~m}$, pipe depth $h$ was $1 \mathrm{~m}$, and frequency $F$ was equal to $20 \mathrm{~Hz}$. One can see that at $c_{R}$ approaching $c_{0}$ from the left a resonance increase of generated ground vibrations occurs. For $c_{R}>c_{0}$ a quick drop in amplitudes takes place characterising exponential decay of the accompanying quasi-static field with distance $y$.

Using the obtained results for the amplitudes of ground vibrations generated by buried pipes, one can evaluate vibrations of the house walls and eventually the levels of structure-borne sound generated by walls inside the house. Simple estimate shows, that if the ground vibrations with the amplitudes of $70 \mathrm{~dB}$ (relative to $10^{-9} \mathrm{~m} / \mathrm{s}$ ) are applied to the building foundation, then the levels of 
the structure-borne sound will be in the range of 40-50 dB (relative to the reference level of $2 \cdot 10^{-5}$ $\left.\mathrm{N} / \mathrm{m}^{2}\right)$.

\section{EXPERIMENTAL INVESTIGATIONS}

Experimental investigations of the environmental low-frequency noise and vibration were carried out in four locations over the East Midlands, using the addresses provided by the members of the Low Frequency Noise Sufferers Association (LFNSA) (for brief discussion see also [23]). The main aims of these investigations were to obtain experimental evidence of the existence of environmental lowfrequency noise at frequencies close to those of infrasound and to check up the above mentioned theoretical hypothesis that under certain circumstances underground gas pipes may be one of its sources.

The experiments comprising high resolution measurements of noise and vibration spectra were carried out inside and outside the complaint's houses, as well as near buried gas distribution lines in the surrounding areas. The equipment included portable FFT spectrum analyser which was used in combination with high-sensitive electret microphone (for noise measurements) and with accelerometers (for measurements of vibration). The measured spectra have been memorised in the FFT spectrum analyser which had an output to a computer.

Initial noise and vibration measurements were made inside the houses: in living rooms, bedrooms, and utility rooms. Afterwards, they were repeated outside the houses: within boundaries of the properties and in relatively remote locations, especially in the vicinity of underground gas 
distribution lines. Special attention has been paid to measuring ground vibration spectra and examining their relationships with measured noise. The results of the investigations have shown that in two properties out of four the environmental low- frequency noise has been detected. In what follows we discuss only these positive cases.

In the first property, located in a very quiet rural area (near Melton Mowbray, Leicestershire), the noise spectra, $L_{p}$, measured inside the house in the frequency range 0-100 $\mathrm{Hz}$ and with a frequency resolution of $1 \mathrm{~Hz}$ showed three very distinctive narrow peaks at frequencies $24.5 \mathrm{~Hz}, 49 \mathrm{~Hz}$ and $73.5 \mathrm{~Hz}$ (see Fig. 4). These resembled the first three Fourier harmonics of the main frequency 24.5 Hz. This noise, which we could clearly hear (probably because of the presence of higher harmonics at 49 and $73.5 \mathrm{~Hz}$ ), was exactly the noise complained of. The amplitudes of the spectral peaks were respectively $46 \mathrm{~dB}, 43 \mathrm{~dB}$ and $34 \mathrm{~dB}$ of the linear scale. That is approximately by $15 \mathrm{~dB}$ higher than the background noise at corresponding frequencies.

Measurements of ground vibration spectra, $L_{a}$, near the house as well as around the suspected underground gas pipes in the nearby area showed the absence of any vibrations above the background level (Fig. 5). For comparison, Figure 6 shows the ground vibration spectrum generated by an inter-city train at a distance of $30 \mathrm{~m}$ from the track. The spectrum in Fig. 6 is in good agreement with theoretically calculated spectra [8]. Note that, because of using the accelerometer, the measured amplitudes of ground vibrations in Figs. 5 and 6 are given in terms of particle acceleration rather than particle velocity, i.e., in $\mathrm{dB}$ relative to the reference acceleration level of $2 \cdot 10^{-6} \mathrm{~m} / \mathrm{s}^{2}$. 
Investigation of environmental low-frequency noise

Attempts undertaken to locate the source of air-borne noise by driving around gave no results, partly because the noise was not steady and occasionally disappeared. Spectral measurements taken near some of the local utility installations, e.g., the electric sub-station (Fig. 7), could not be related to the noise measured in the house. Thus, in the above mentioned case there was no experimental evidence that the low-frequency noise complained of was caused by ground vibrations generated by underground gas pipes. Moreover, according to the theoretically calculated spectra of ground vibrations from underground pipes, which are broad and smooth (see Fig. 2), it was unlikely to expect generation of the associated structure-borne noise at three distinctive harmonics. The presence of these three harmonics in the spectra of measured noise allows us to suggest that in the particular case under consideration the source responsible for the noise represented a vibrating body oscillating with high amplitudes at the main frequency of $24.5 \mathrm{~Hz}$. Then the appearance of higher harmonics in noise spectra could be attributed to nonlinear distortions of the body vibration.

In the second case of the positive indication of the low-frequency noise, the property was also in a quiet rural location (near Bunny, Nottinghamshire). In this last case it was possible not only to detect low-frequency noise inside and outside the house, but also to identify and locate the source of the noise. Since this case gives a good illustration of the methodology of measurements, we describe it in more detail.

The noise spectrum inside the house can be seen in Fig. 8 for the frequency range $0-100 \mathrm{~Hz}$ (this spectrum and the ones described below have been measured with higher frequency resolution: 0.125 $\mathrm{Hz}$ ). One can see two distinctive peaks above the background noise level: at $19.5 \mathrm{~Hz}$ and $27 \mathrm{~Hz}$. The corresponding amplitudes are $42 \mathrm{~dB}$ and $36 \mathrm{~dB}$ of the linear scale. Measurement outside the house 
(Figure 9) showed only one of the peaks left: at $19.5 \mathrm{~Hz}$. Thus, the maximum at $27 \mathrm{~Hz}$ measured inside the house was caused probably by excitation of one of the room resonances. Note that the amplitude of the peak at $19.5 \mathrm{~Hz}$ outside the house is around $48 \mathrm{~dB}$, i.e., the sound level inside the house is only by $6 \mathrm{~dB}$ lower than outside. Spectra of ground vibrations measured outside the house indicated no vibrations above the background level. In particular there were no any increase of vibration amplitudes in the frequency range around $19.5 \mathrm{~Hz}$. Thus, it was clear that the noise complained of is the air-borne noise.

Driving around the area and measuring the noise spectra outside the car enabled us to locate the source by observing the increase in amplitude at the frequency of interest (19.5 Hz). It has been found that the source was located on the territory of the nearby industrial works, i.e., approximately in 2 miles from the complaint's house.

Figure 10 shows the noise spectrum measured on the road leading to the above mentioned industrial works. Note that the amplitude of the now split peak with the central frequency of $19.5 \mathrm{~Hz}$ is up to $58 \mathrm{~dB}$ (i.e., by $10 \mathrm{~dB}$ higher than near the house). The additional significant peak around 70 $\mathrm{Hz}$, which has not been present in the spectra measured near the complaint's house, was probably caused by a side local source which was out of our attention. Finally, the noise spectrum measured near the territory of the industrial works is shown in Fig. 11. It can be seen that the amplitude of the peak at $19.5 \mathrm{~Hz}$ is now $65 \mathrm{~dB}$. Thus, the source responsible for the low-frequency noise complained of might be one of the installations located in the territory of the industrial works, e.g., manufacturing rigs or chimneys. Unfortunately, the more definite identification of the source was not possible without access to the territory. 
Investigation of environmental low-frequency noise

\section{DISCUSSION}

The above described investigation of the environmental low-frequency noise have demonstrated the following.

Theoretical study has proved that generation of the low-frequency noise by underground gas pipes is feasible. In this case the disturbing low-frequency noise (hum) may be considered as structure-borne noise generated by ground vibrations propagating to buildings as surface Rayleigh waves. These waves can be generated by buried underground gas pipes in which turbulent gas flows excite sound waves of high amplitude propagating in a pipe-line as in a waveguide. Such a generation takes place if the velocities of sound $c_{0}$ inside the pipes (450 m/s for methane) are higher than the velocities of Rayleigh surface waves $c_{R}$ in the ground. Especially large resonance increase may occur for $c_{0}$ slightly higher than $c_{R}$. The physical nature of this phenomenon is similar to that of sound boom from supersonic jets or to that of recently predicted Rayleigh ground wave boom from superfast trains.

Experimental measurements of noise and vibration in and near complaint's houses have demonstrated that in two locations out of four (i.e., in $50 \%$ of cases under investigation) the low frequency noise complained of has been detected. Spectra of noise in both cases were completely different. Therefore, they have to be associated with different noise sources. This confirms the point of view that the nature of environmental low-frequency noise can not be reduced to one general 
mechanism of a national or global scale. There is a variety of sources and mechanisms of environmental low-frequency noise depending on particular circumstances.

The presence of environmental ground vibrations above the background level has not been observed in any location. Thus, at least during this series of experiments, there was no evidence of underground gas pipes being a source of low frequency noise. The reason for this could be low amplitudes of sound generated inside the pipes, for example because of gas flow speed being insufficiently high to cause efficient excitation of sound by turbulence. This does not mean, however, that this mechanism should be excluded from further consideration.

The measured spectra of the air-borne low-frequency noise consisted of a few low-level tonal components with the amplitudes inside houses up to $50 \mathrm{~dB}$ of the linear scale. This level is generally below the averaged threshold of human sensitivity corresponding to A-weighting curve. Therefore, only people characterised by high sensitivity to low-frequency sound and living in quite rural locations can be affected. Nevertheless, even though a number of such people is relatively small, these cause quite specific physiological and legal aspects related to individual perception of lowfrequency noise [24], in particular the increased annoyance of tonal components [25]. We did not touch these aspects in the present work, concentrating on physical mechanisms of the low-frequency noise. However, in our opinion, the measurement techniques and the corresponding legal aspects of this problem could become a subject of special discussion. 
Investigation of environmental low-frequency noise

\section{CONCLUSIONS}

(1) Theoretical study has proved that generation of the low-frequency noise by underground gas pipes is feasible.

(2) Experimental measurements of noise and vibration in and near complaint's houses have confirmed that the environmental low-frequency noise (or hum) does exist.

(3) At least during this series of experiments, there was no evidence of underground gas pipes being a source of environmental low-frequency noise.

(4) The experiments show that there is a variety of mechanisms and sources of environmental lowfrequency noise, rather than one general mechanism of a national or global scale.

(5) The measured spectra of the air-borne low-frequency noise comprise a few low-level tonal components which are generally below the averaged threshold of human sensitivity.

(6) Even though a number of people sensitive to environmental low-frequency noise is relatively small, the technical, physiological and legal aspects of the problem deserve special discussion.

\section{ACKNOWLEDGEMENT}

The author is grateful to the Royal Society for financial support of this investigation. 


\section{REFERENCES}

1. Tempest, W., A survey of low frequency noise complaints received by local authorities in the United Kingdom. Journ. Low Frequency Noise and Vibration, 8 (1989) 45.

2. Persson, K. and Rylander, R., Disturbance from low frequency noise in the environment - a survey among the local environmental health authorities in Sweden. Journ. Sound and Vibration, 121 (1988) 339-345.

3. Broner, N., The effects of low frequency noise on people. A review. Journ. Sound and Vibration, 58 (1978) 483-500.

4. Vasudevan, R.N. and Leventhal, H.G., A study of annoyance due to low frequency noise in the home. Journ. Low Frequency Noise and Vibration. 1(4) (1982) 157-164.

5. Howell, K. and Weatherilt, P.F., A review of low frequency noise investigations by British Gas. Report, British Gas, London, May 1992.

6. Sargent, J.W., Low frequency noise. Report, Building Research Establishment, UK, Garston, October 1994.

7. Sargent, J.W., Study of environmental low frequency noise. Acoustics Bulletin, 20 (1995) 39-41.

8. Krylov, V.V. and Ferguson, C.C., Calculation of low-frequency ground vibrations from railway trains. Applied Acoustics, 42 (1994) 199-213.

9. Krylov, V.V. Low-frequency ground vibrations from underground trains. Journ. Low Frequency Noise and Vibration, 14(1) (1995) 55-60. 
Investigation of environmental low-frequency noise

10. Hollingworth, G.H. and Gilbert, D.A.M., An exploratory study into the prediction of low frequency traffic noise. Applied Acoustics, 15 (1982) 79-96.

11. Krylov, V.V., Ground vibrations from accelerating and braking road vehicles. In: Proc. 15th International Congress on Acoustics, Trondheim, Norway, 26-30 June 1995, Ed. M. Newman, Vol. 2 (1995) 161-164.

12. Augustynska, D., Infrasonic noise emitted by flow mashines, its sources and reduction methods. Journ. Low Frequency Noise and Vibration 8 (1) (1989) 9-15.

13. Imaichi, K., Tsujimoto,Y. and Takabatake, S., Theoretical analysis of infrasound radiation from an oscillating bridge. Journ. Sound and Vibration. 81 (1982) 453-468.

14. Goroumaru, H., Shiraishi, K., Hara, H. and Komori, T., Prediction of low frequency noise radiated from vibrating highway bridges. Journ. Low Frequency Noise and Vibration, 6(4) (1987) 155-166.

15. Krylov, V.V., On one possible mechanism of the low-frequency hum. Proc. I.O.A., 17(4) (1995) 9-16.

16. Krylov, V.V., On the theory of railway-induced ground vibrations. Journ. de Phys. IV, 4 (1994) C5-769-772.

17. Krylov, V.V., Generation of ground vibrations by superfast trains. Applied Acoustics, 44 (1995) 149-164.

18. Junger, M.C. and Feit, D. Sound, Structures, and Their Interaction, Acoust. Soc. Amer., New York, 1993. 
19. Jette, A.N., Morris, M.S., Murphy, J.C. and Parker, J.G., Active acoustic detection of leaks in underground natural gas distribution lines. Materials Evaluation 35 (1977) 90-99.

20. Jette, A.N. and Parker, J.G., Excitation of an elastic half-space by a buried line source of conical waves. Journ. Sound and Vibration, 67 (1979) 523-531.

21. Michalke, A., On the propagation of sound generated in a pipe of circular cross-section with uniform mean flow. Journ. Sound and Vibration, 134 (1989) 203-234.

22. Meissner, M.W. and Czechowicz, M.R., Experimental investigation of flow-induced acoustic oscillations in a piping system with closed branches, Applied Acoustics, 45 (1995) 359-375.

23. Krylov, V.V., Measurements of environmental low-frequency noise. Proc. I.O.A., 18(1) (1996), 21-28.

24. Frost, G.P., An investigation into the microstructure of the low frequency auditory threshold and of the loudness function in the near threshold region, Journ. Low Frequency Noise and Vibration, 6(1) (1987) 34-39.

25. Landström, U., Åkerlund, E., Kjellberg, A., and Tesarz, M., Exposure levels, tonal components, and noise annoyance in working environments. Environment International, 21 (1995) 265-275. 
Investigation of environmental low-frequency noise

\section{FIGURE CAPTIONS}

Fig.1. On the explanation of ground vibration generation mechanism associated with underground gas pipes

Fig.2. Calculated spectra of ground vibration velocity $(\mathrm{m} / \mathrm{s})$ for different pipe-depths: $h=0.5,1.0$ and $1.5 \mathrm{~m}$ (curves $\mathrm{V} 1, \mathrm{~V} 2$ and V3 respectively)

Fig.3. Calculated amplitudes of ground vibration velocity $(\mathrm{m} / \mathrm{s})$ at the frequency $20 \mathrm{~Hz}$ as functions of Rayleigh wave velocity of the ground, $c_{R}$, for different parameters of ground attenuation: $\gamma$ $=0.005,0.010$ and 0.015 (curves V1, V2 and V3 respectively)

Fig.4. Noise spectrum measured inside the house (first case)

Fig.5. Spectrum of ground vibration acceleration (in $\mathrm{dB}$ relative to $2 \cdot 10^{-6} \mathrm{~m} / \mathrm{s}^{2}$ ) measured near the house (first case)

Fig.6. Spectrum of ground vibration acceleration (in $\mathrm{dB}$ relative to $2 \cdot 10^{-6} \mathrm{~m} / \mathrm{s}^{2}$ ) generated by an inter-city train at the distance of $30 \mathrm{~m}$ from the track 
V. V. Krylov

Fig.7. Noise spectrum measured near the electric sub-station

Fig.8. Noise spectrum measured inside the house (second case)

Fig.9. Noise spectrum taken outside the house (second case)

Fig.10. Noise spectrum measured on the road

Fig.11. Noise spectrum measured in the proximity of the nearby industrial works 


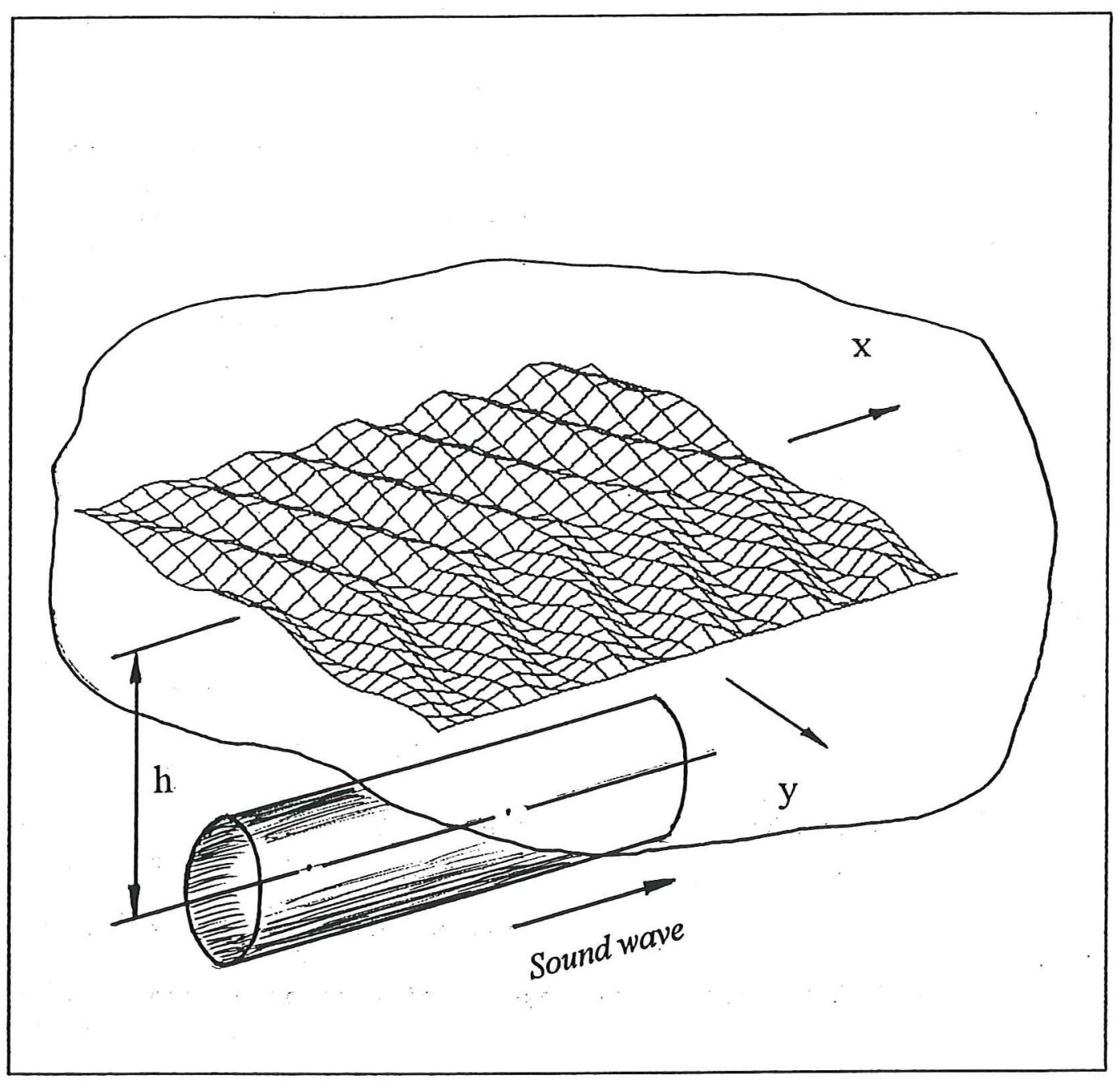

Fig. 1 


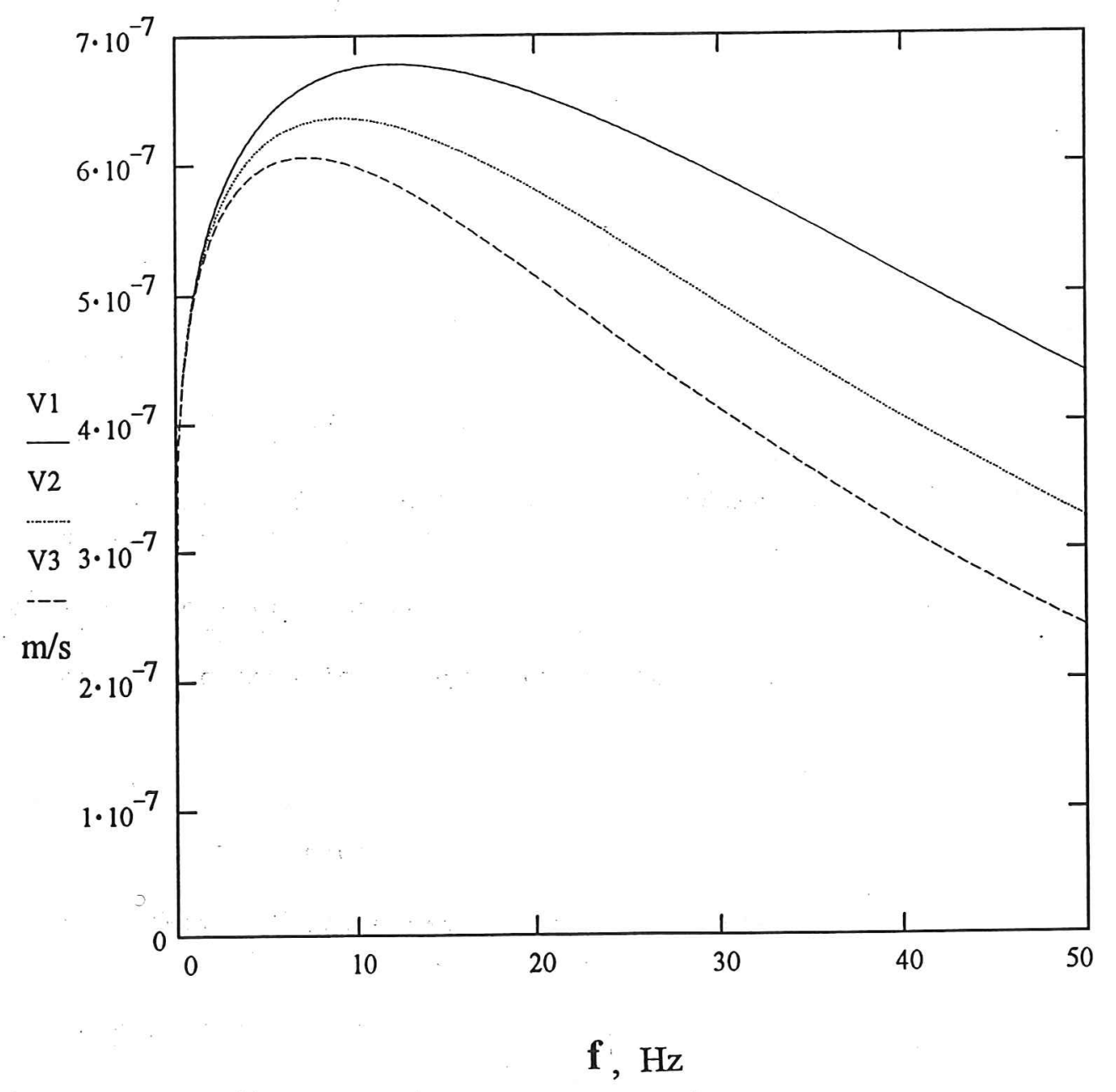

Fig. 2 


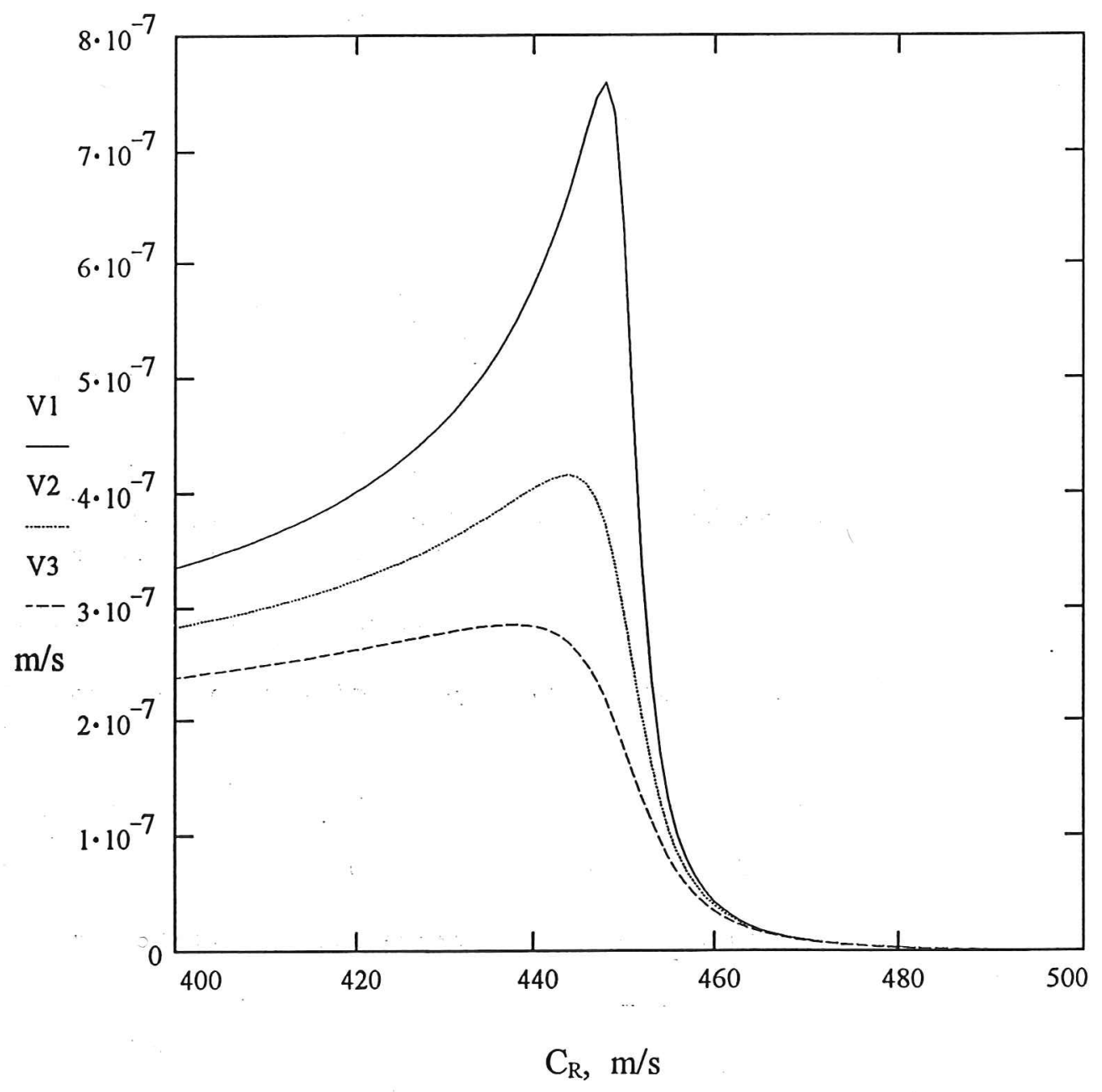

Fig. 3 


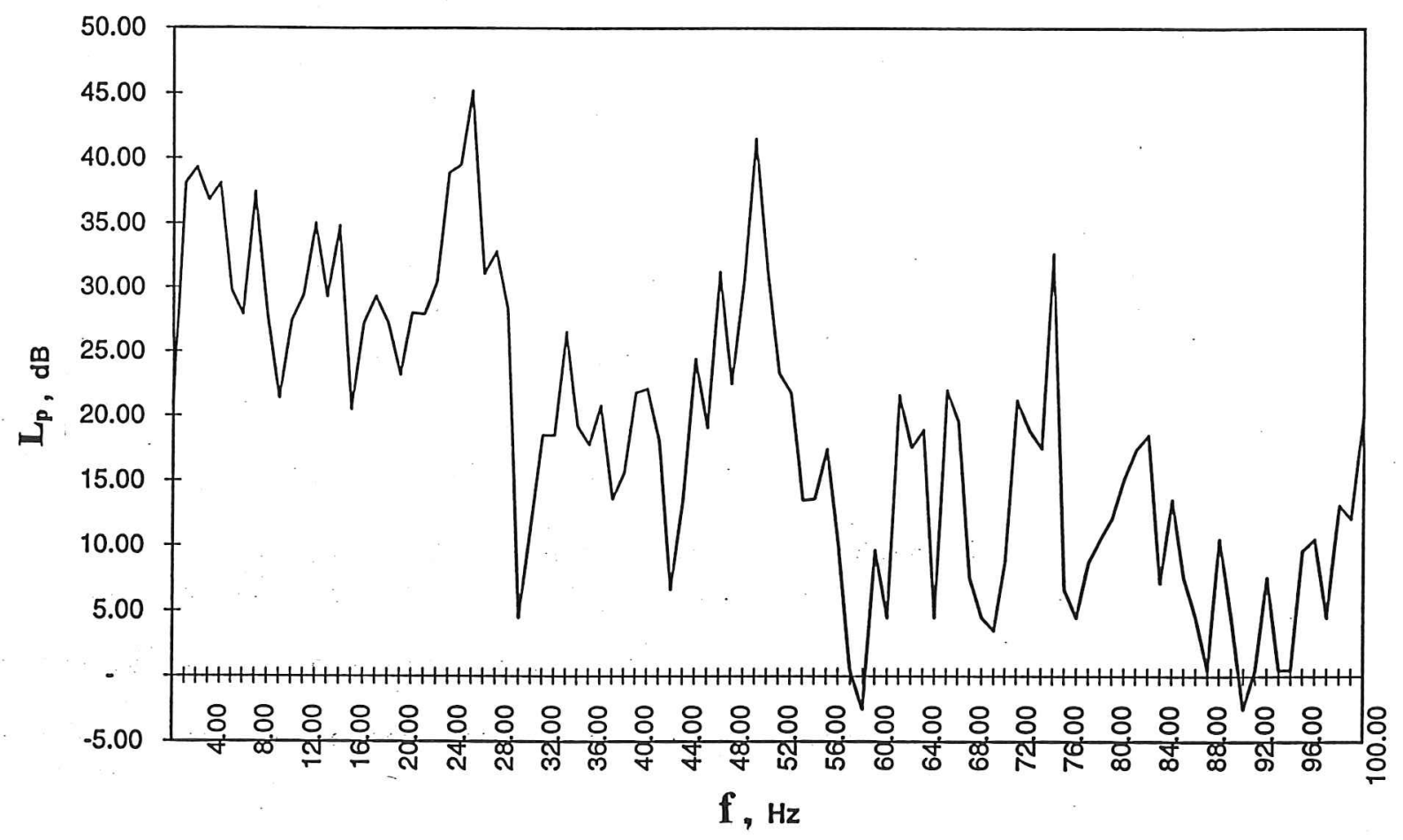

Fig. 4 


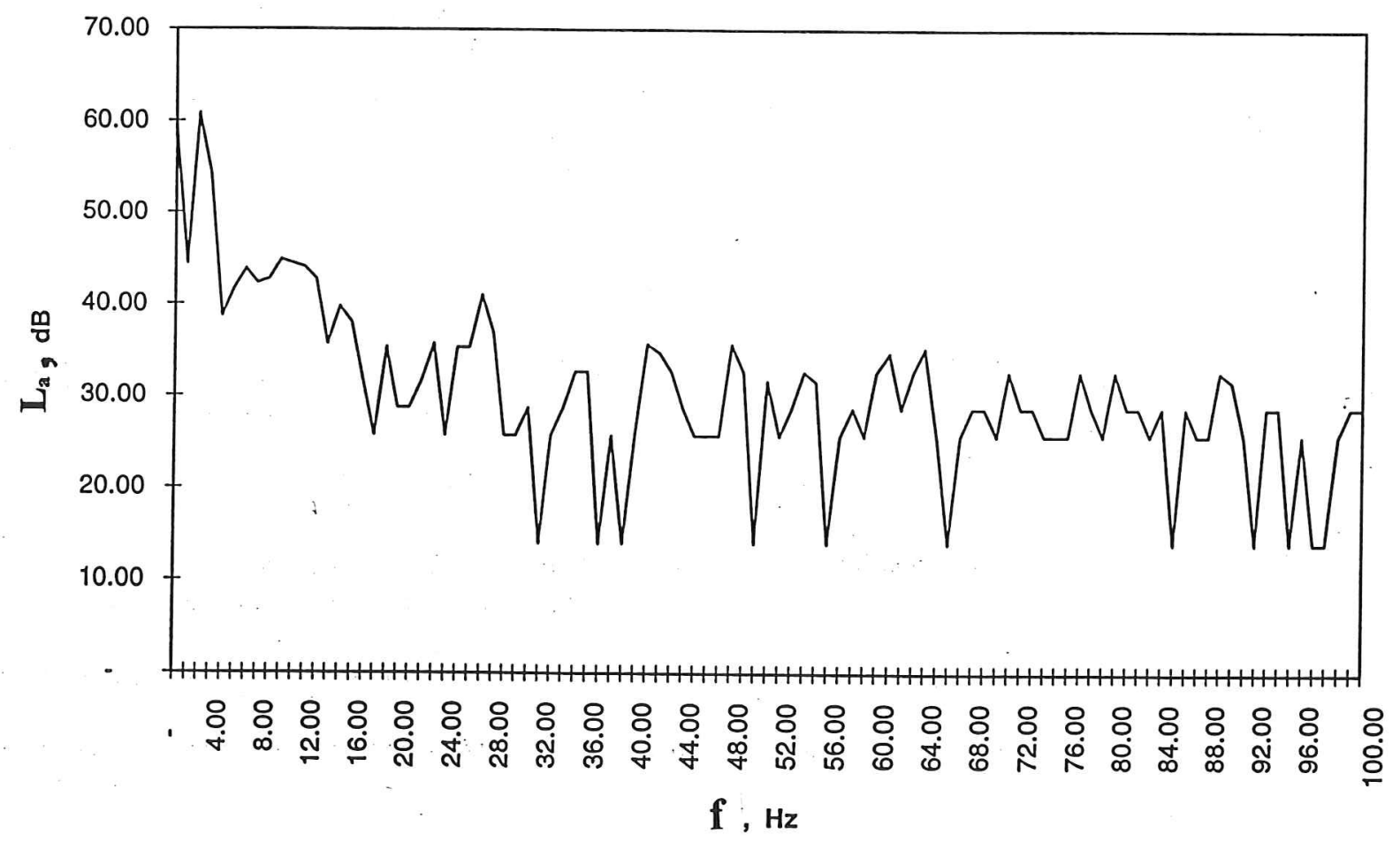

Fig. 5 


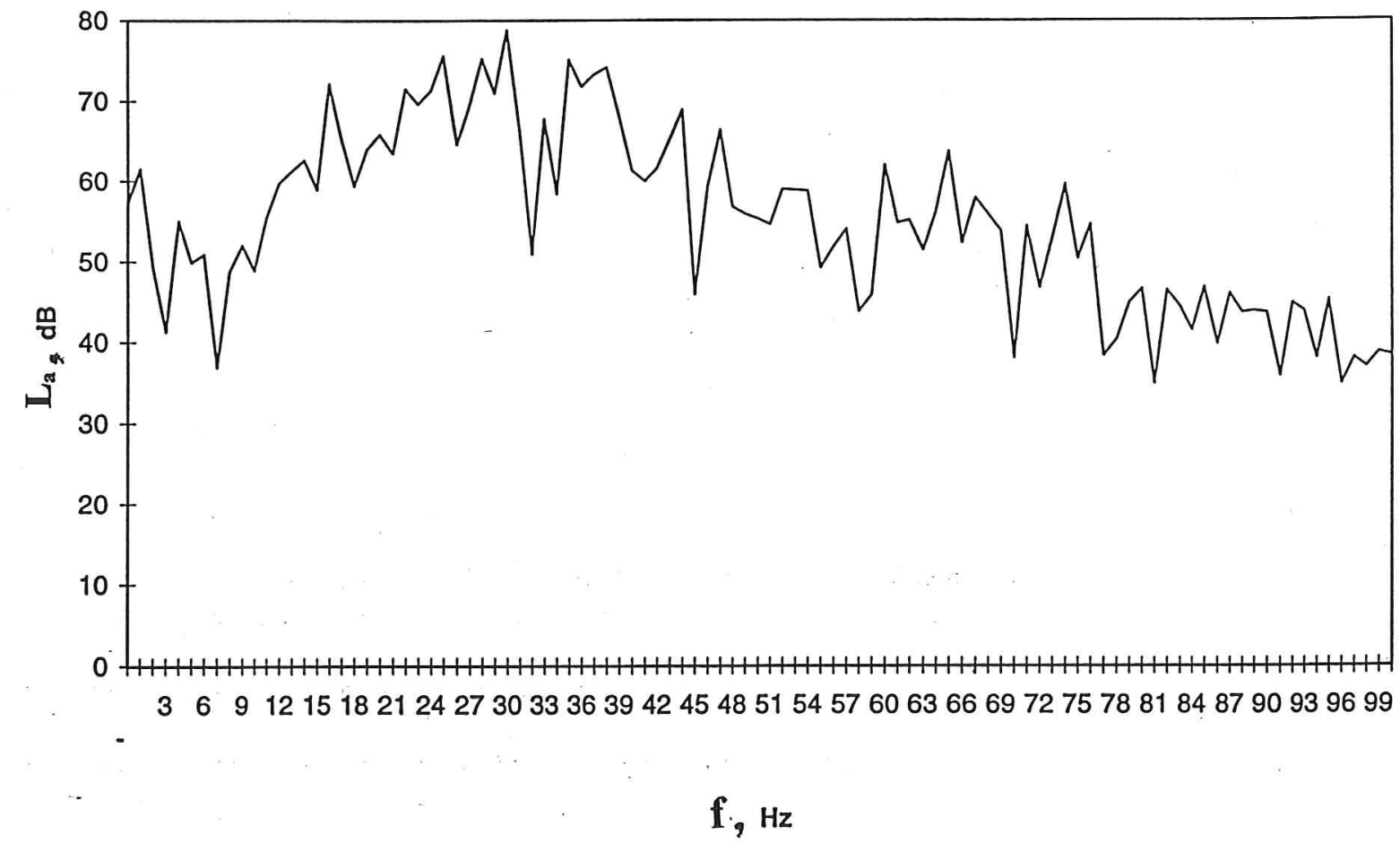

Fig. 6 


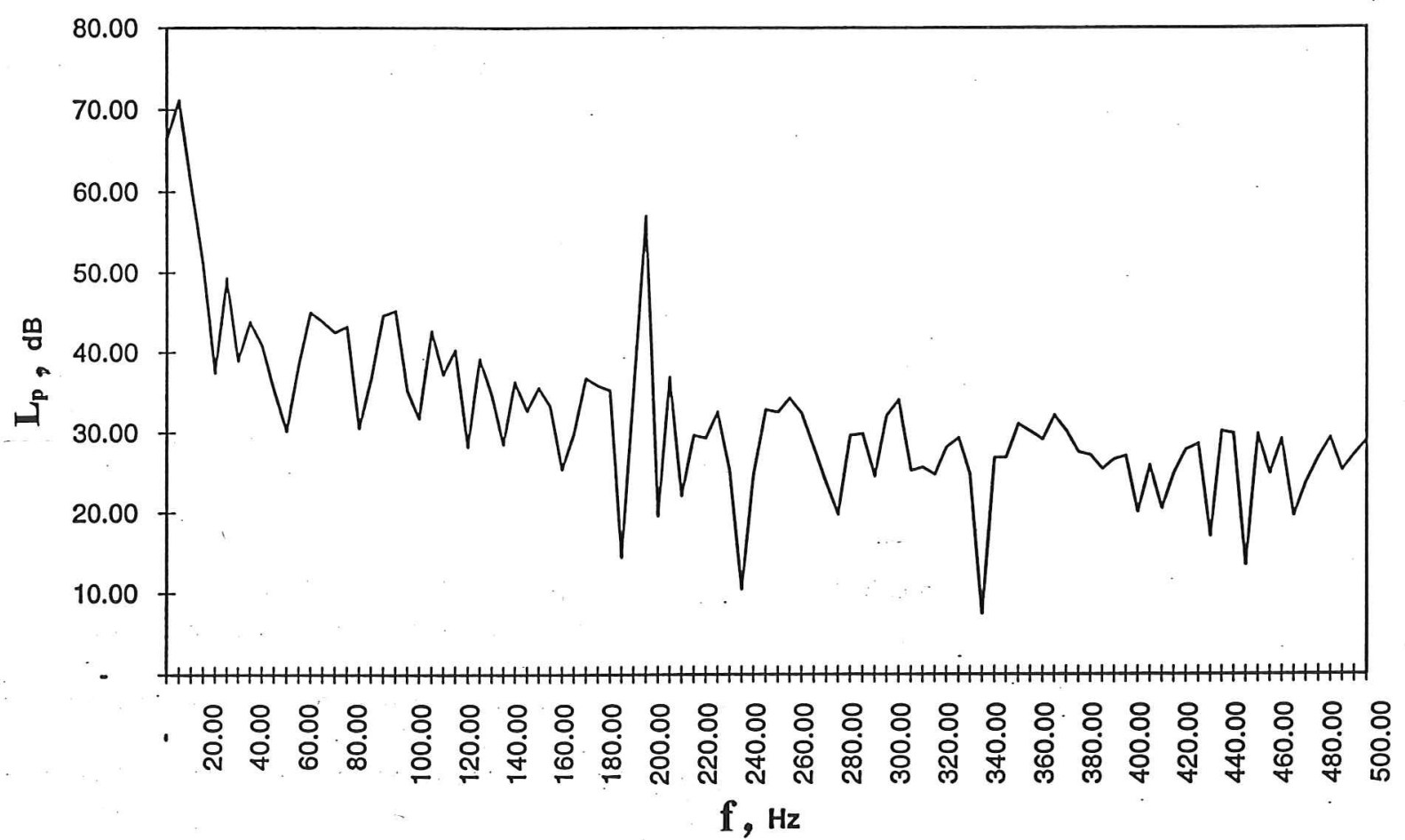

Fig. 7 


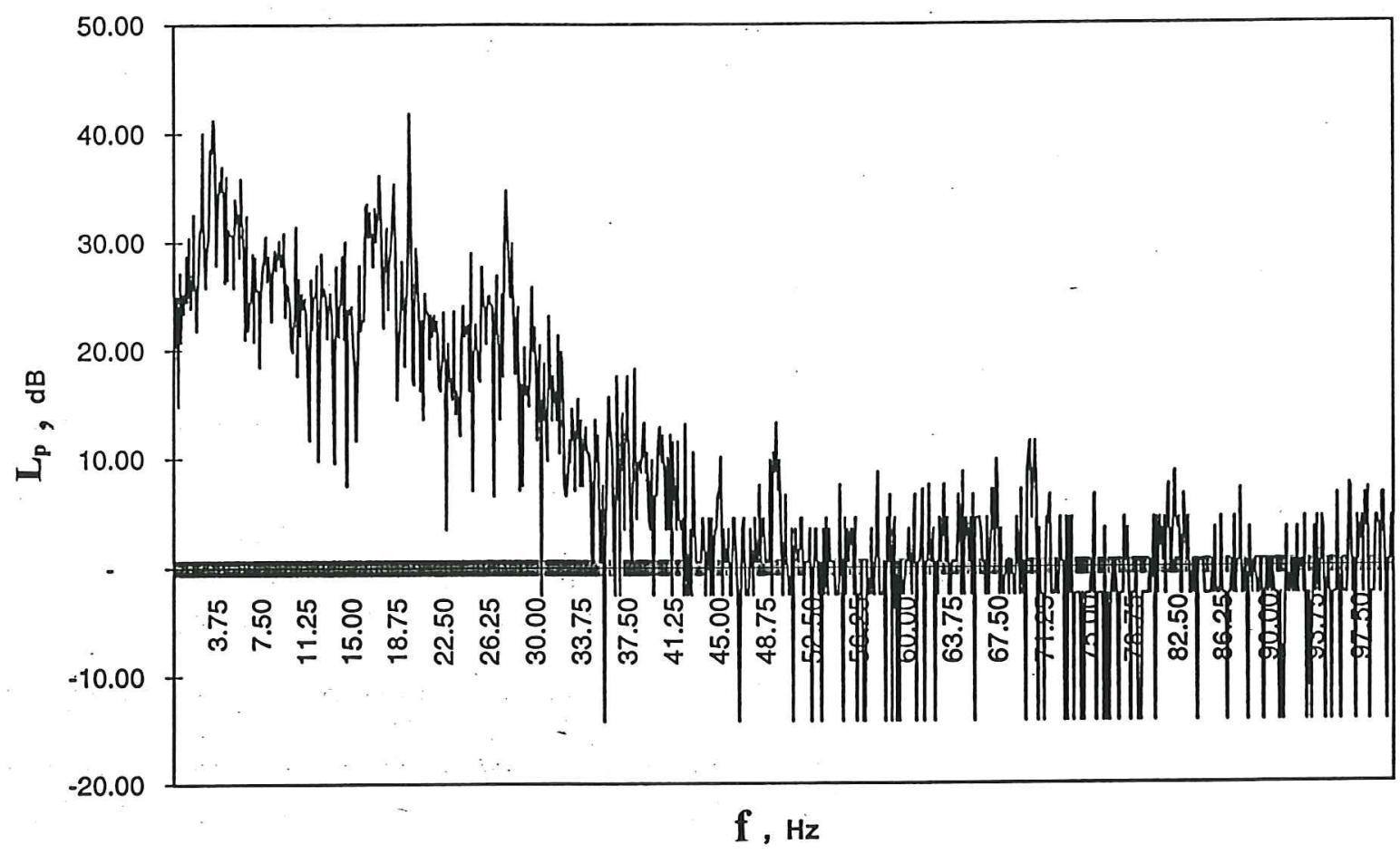

Fig. 8 


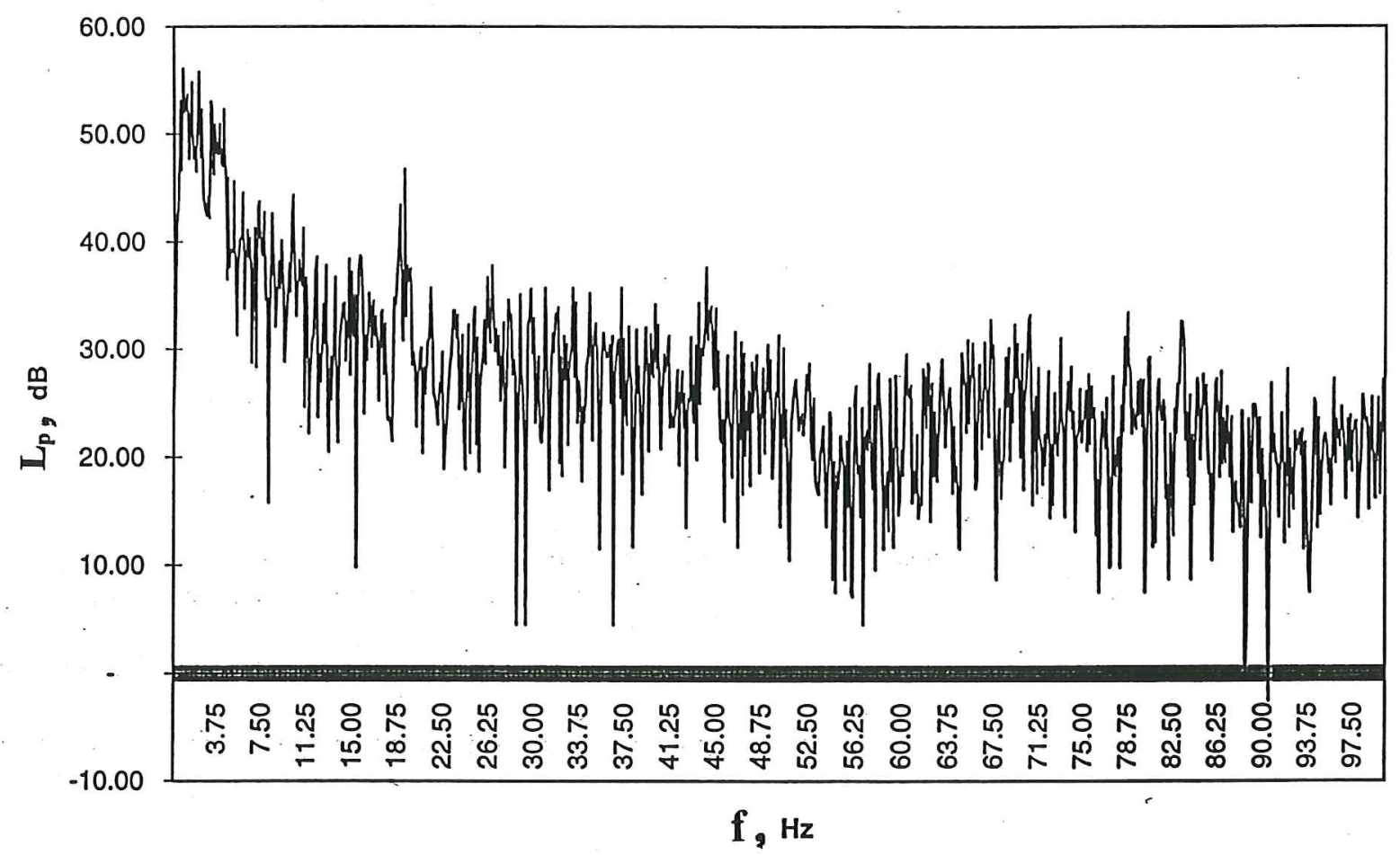

Fig. 9 


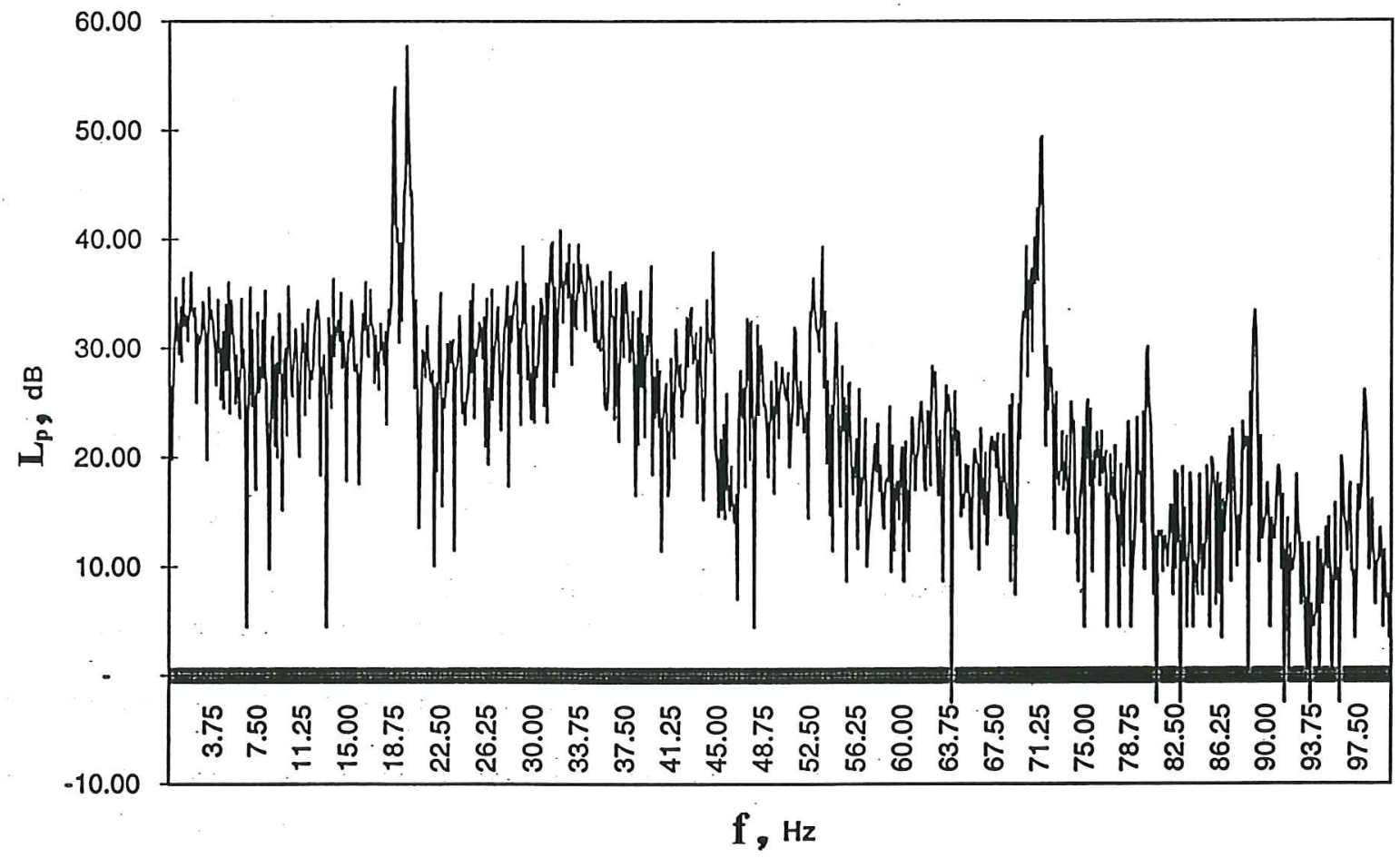

Fig. 10 


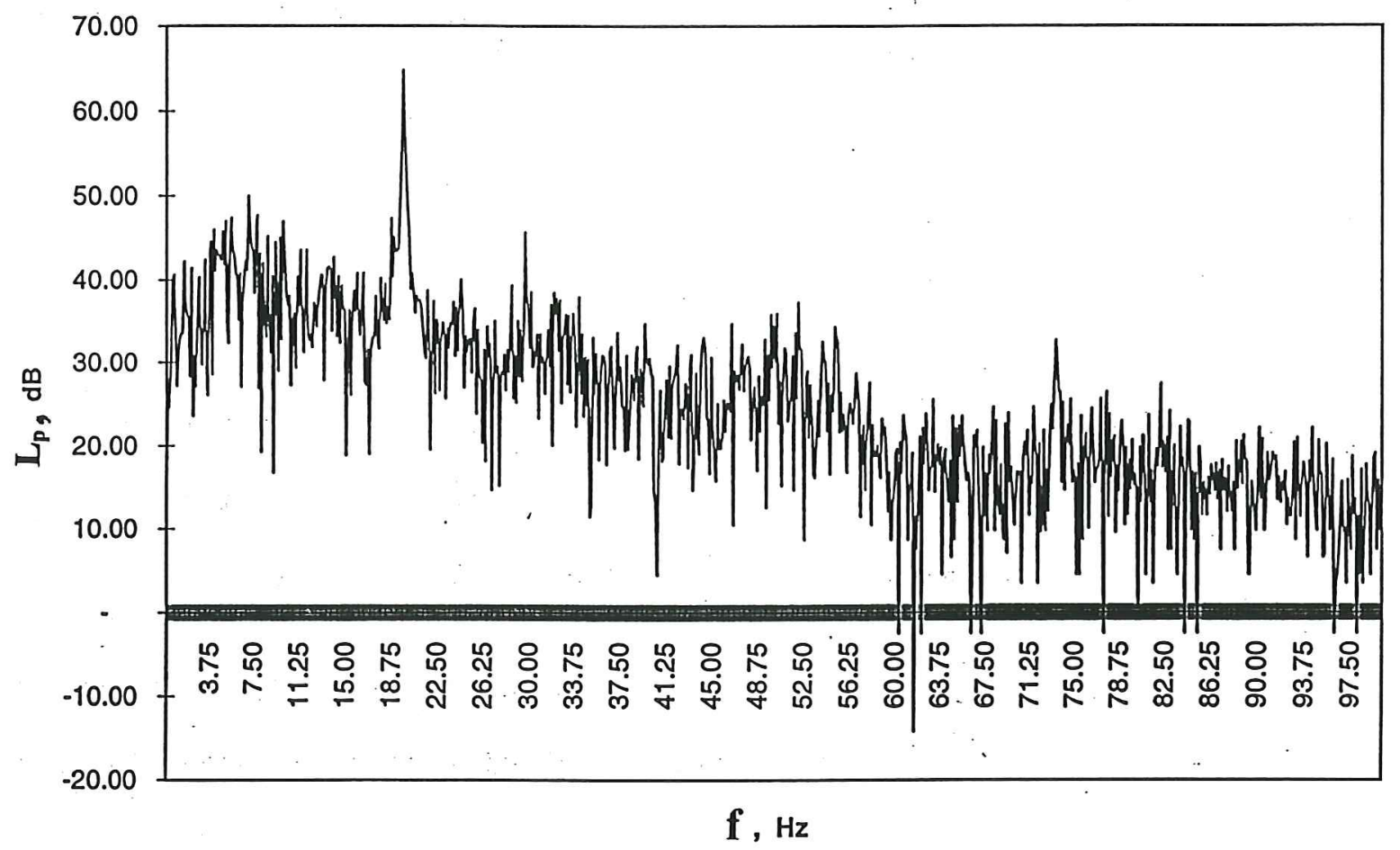

Fig. 11 